\title{
Memorias de un Servicio de Cirugía General y de sus cirujanos. Parte 2
}

\author{
Memories of a General Surgery Service and its surgeons. Part 2
}

David Olvera Pérez*

\author{
CRONOLOGÍA DEL SERVICIO DE \\ CIRUGÍA GENERAL Y \\ DE LOS CIRUJANOS GENERALES DEL \\ HOSPITAL \\ GENERAL DEL CENTRO MÉDICO \\ NACIONAL DEL INSTITUTO \\ MEXICANO DEL SEGURO SOCIAL \\ 1963-1981, (HG DEL CMN DEL IMSS) \\ DR. GUSTAVO BAZ PRADA \\ (1894-1987) (Figura 1)
}

$\mathrm{N}$ ació en Tlalnepantla, Estado de México, el 01 de mayo del año 1894. Recordar a un hombre, revolucionario, político, maestro, un gran mexicano y sobre todo a un cirujano notable es un honor, para que las generaciones médico-quirúrgicas presentes y futuras sepan sus orígenes y no olviden que el presente fue realizado por gente pensante y modificadora de su tiempo. Obligación que también nos corresponde realizar.

Lo conocí en el ocaso de su vida, muchos domingos platicamos al medio día y siempre me impresionó su inteligencia y creatividad, siempre tenía alguna novedad que deseaba emprender. Como cirujano, tuve la oportunidad de ayudarle en una apendicectomía -ila última que realizó?- en la joven hija de un amigo suyo, y a pesar de su edad-más de 80 años- me sorprendió su rapidez y técnica, parecía un pez en el agua, puedo decir que lo vi operar, el ayudante no fue necesario. A continuación recordaremos algunos pasajes de su vida, su herencia política, académica y profesional.

La juventud siempre fue una de sus preocupaciones, para muestra escribió:

El tiempo y el viento se van y no vuelven... La historia se escribe en la hoja del tiempo... La juventud, como el tiempo se va y no vuelve... iJuventud: escribe tu historia en la hoja del tiempo...

Y deja que el viento se lleve el triunfo y la gloria!

Su tesis de cirujano sobre "cirugía vascular" marcó el inicio de un cirujano inconforme, que buscó y adquirió experiencia en el extranjero, aplicándola en el México de su época en sus sistemas de hospitales, en la vida universitaria y en la política. Realizó el primer trasplante de riñón experimental (Figura 2) y el primer injerto de aorta, implantó técnicas de asepsia y antisepsia, vistió a los médicos de blanco y sus técnicas quirúrgicas personales fueron reconocidas, copiadas y elogiadas. ${ }^{1}$

Sus logros profesionales y su dedicación a la enseñanza lo llevaron a ocupar la Dirección de la Escuela Nacional de Medicina y al mismo tiempo de la Escuela Médico Militar, con el fin de unificar y mejorar los planes de estudio ya con el grado de General (Figura 3 A y B). Es importante resaltar este hecho, pues no tengo información de que un mis-

Citar como: Olvera PD. Memorias de un Servicio de Cirugía General y de sus cirujanos. Parte 2. Cir Gen. 2020; 42 (3): 232-244. https://dx.doi.org/10.35366/99966 


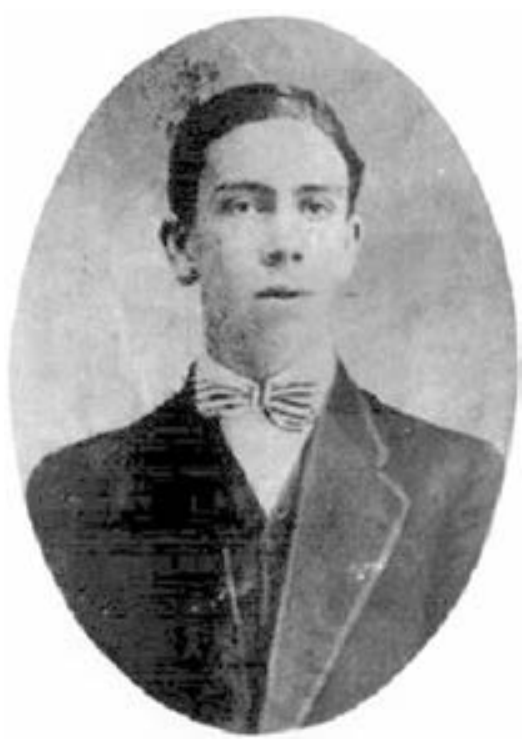

Figura 1: Gustavo Baz Prada, 1912.

mo individuo haya conseguido dos veces el generalato. En el año de 1936 implantó el Servicio Médico Social de los estudiantes de medicina, con el objetivo de contribuir al mejoramiento de la salubridad de los grupos más necesitados y para brindar a los pasantes de Medicina la oportunidad de poner en práctica sus conocimientos con antelación a su graduación; ${ }^{1}$ y el 07 de julio de 1937 nace el Pentatlón Deportivo Militar Universitario,

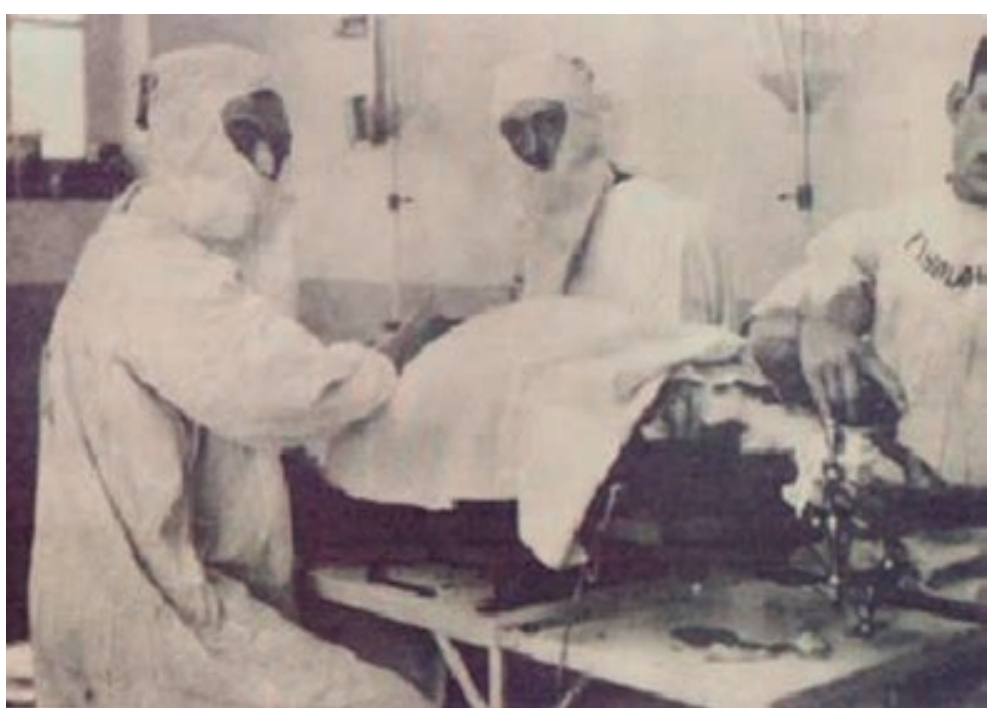

Figura 2: Trasplante experimental de riñón en perro, 1919. para contribuir al desarrollo de los estudiantes universitarios, con actividades deportivas, sociales y con disciplina militar. Entre los alumnos fundadores se encontraban Jorge Jiménez Cantú, Armando León Bejarano y Luis Sáenz Arroyo ${ }^{1}$ (Figura 4).

En el mes de junio de 1938 fue electo rector de la Universidad Nacional Autónoma de México, cargo desde el que contribuyó a elevar los estándares académicos y el prestigio universitario (Figura 5). Solamente permaneció dos años en tan alto puesto académico. Su renuncia nunca fue aceptada, por lo que nunca dejó de pertenecer a la universidad. En ese mismo año, en el mes de diciembre el Consejo Universitario le otorgó el nombramiento de "Doctor Honoris Causa". ${ }^{2}$

Como rector regularizó y reorganizó los ciclos escolares y el cuerpo docente; en pocas palabras, mejoró a la universidad, pues ocupaba un lugar entre las cinco más malas del mundo. Durante su gestión, tuvo otro acierto para la juventud, fundó el Pentatlón Deportivo Militarizado Universitario.

Es necesario hacer una pausa para regresar al pasado, reiniciar su biografía cronológicamente, y entrar en la novela, en la leyenda y en la historia.

El Dr. Gustavo Baz Prada nació en el Municipio de Tlalnepantla, en el Estado de México, el 01 de mayo de 1894. Y por los eminentes servicios prestados al pueblo mexicano y a su entidad federativa, el 23 de diciembre de 1978, la Legislatura Estatal decretó que el Municipio de Tlalnepantla se denominaría Tlalnepantla de Baz. ${ }^{3}$

Desde niño se distinguió por su seriedad y dedicación, y demostró tener gran inteligencia que le permitió sobresalir en todos los puestos que desempeñó, como ejemplo podemos leer la siguiente frase: "el trabajo y el valor, juntos y sostenidos por largo tiempo, sobrepasan los obstáculos" escribió en francés, a la edad de nueve años.

Muy joven se integró al ejercito zapatista. Contaba apenas con 19 años, cuando despertó en la Sierra del Ajusco al lado de los zapatistas. Su labor y las tareas encomendadas siempre fueron realizadas por el joven Baz con eficiencia, por lo que pronto fue ascendido a Teniente Coronel de Caballería del Ejército Libertador y 

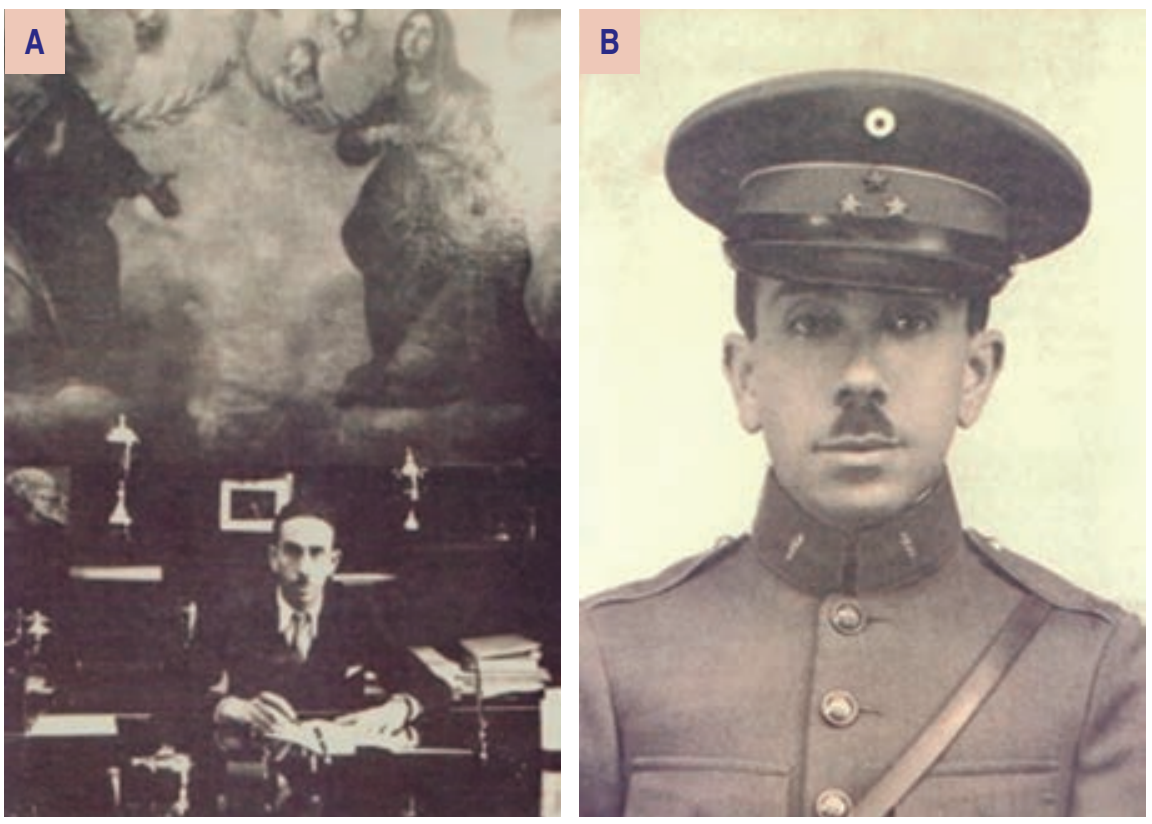

Figura 3: A) Dr. Gustavo Baz Prada. Director Escuela Nacional de Medicina, UNAM. B) Director Escuela Médico Militar.

posteriormente a Coronel, nombramientos que fueron firmados por Emiliano Zapata. ${ }^{4}$

Poco tiempo pasó, en el mes siguiente, para ser exacto el 14 de diciembre, una junta de jefes revolucionarios reunidos en Toluca, determinó nombrarlo Gobernador provisional del Estado. ${ }^{4}$ Solamente había vivido 20 años y durante 11 meses gobernó a su estado, sorprendiendo a todos con su capacidad organizativa, y su visión económica y política (Figura 6).

La experiencia de haber conocido al General Zapata, de haber sido su correo de confianza, le produjo una impresión profunda y permanente. Al triunfo carrancista, retoma su camino en la vida estudiantil, no sin antes haber renunciado a su grado de general revolucionario. "La revolución había perdido un general, pero el país había ganado un gran cirujano", escribió uno de sus biógrafos. ${ }^{5}$ Fue amigo, médico, cirujano, consejero y colaborador de muchos presidentes. En 1942, con el General Manuel Ávila Camacho como Presidente de México, creó la Secretaría de Salubridad y Asistencia, al fusionar la Secretaría de Asistencia con el Departamento de Salubridad ${ }^{6}$ (Figura 7). Bajo su dirección, esta Secretaría sentó las bases del mayor sistema hospitalario, nunca conocido en nuestro país.

Entre sus obras se encuentran el CMN del IMSS desaparecido con el temblor de 1985, los institutos de cardiología, nutrición, hospital infantil y la mayor parte de los hospitales de muchos municipios, a lo largo y ancho del país. Promovió en forma intensa y planificada el envío de jóvenes médicos al extranjero, 480 cifra reconocida. Fue gracias a esto que los institutos pudieron crecer y fructificar. También a él se le deben los certificados prenupciales, y el uso de bata blanca dentro de los quirófanos.

Había alcanzado relieve en su profesión de manera indiscutida e indiscutible, y nuevamente monta el corcel, noble animal, donde el hombre se transforma en caballero, y donde su palabra, vale tanto como su vida. El ciudadano Baz Prada, afrontó sus circunstancias y siempre rescató su palabra empeñada. Fue hombre de su tiempo, pero también sus acciones lo adelantaron a su tiempo. Gustavo Baz, "Hombre Proteico" como le ha llamado uno de sus biógrafos -el maestro Don Andrés Serra Rojas- resurgió en la política a los sesenta años. ${ }^{7}$ 
Cuarenta y tres años después, el ciudadano Gustavo Baz Prada es nuevamente gobernador de su estado. Pero en esa ocasión llegó por la vía política (Figura 8). Durante su gestión, estimuló y promovió el crecimiento del ejército del trabajo, construyó la Ciudad Universitaria en Toluca, realizó el primer congreso nacional agrario y desarrolló la industria automotriz. Siempre luchó para que desaparecieran las carencias de la vida, porque las aprendió desde muy joven, al vivir con los desamparados. A los

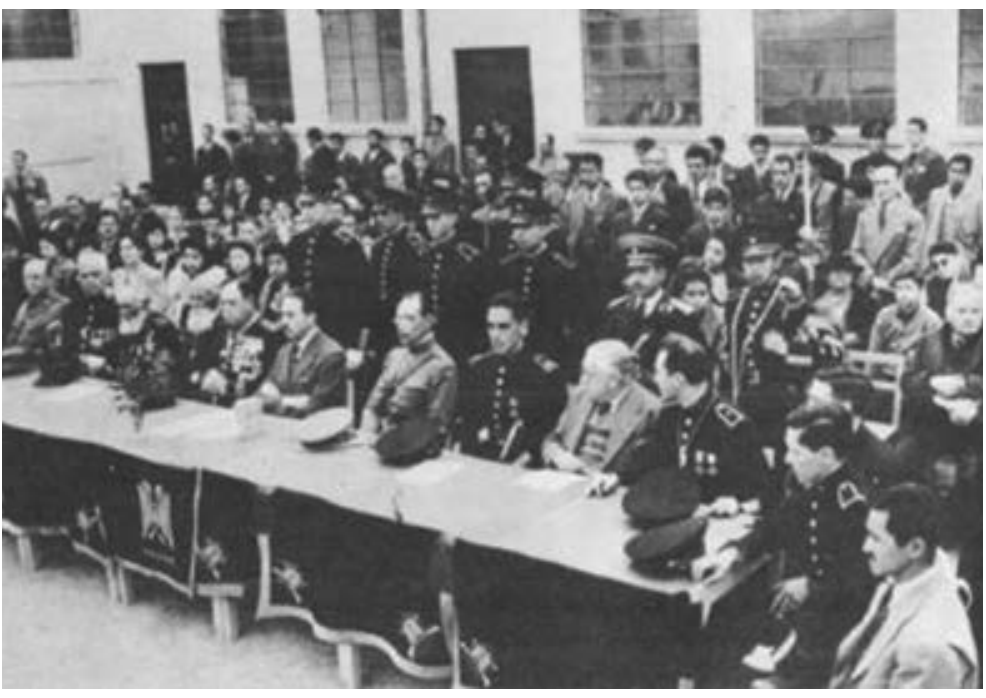

Figura 4: Fundación del Pentatlón Deportivo Militar Universitario.

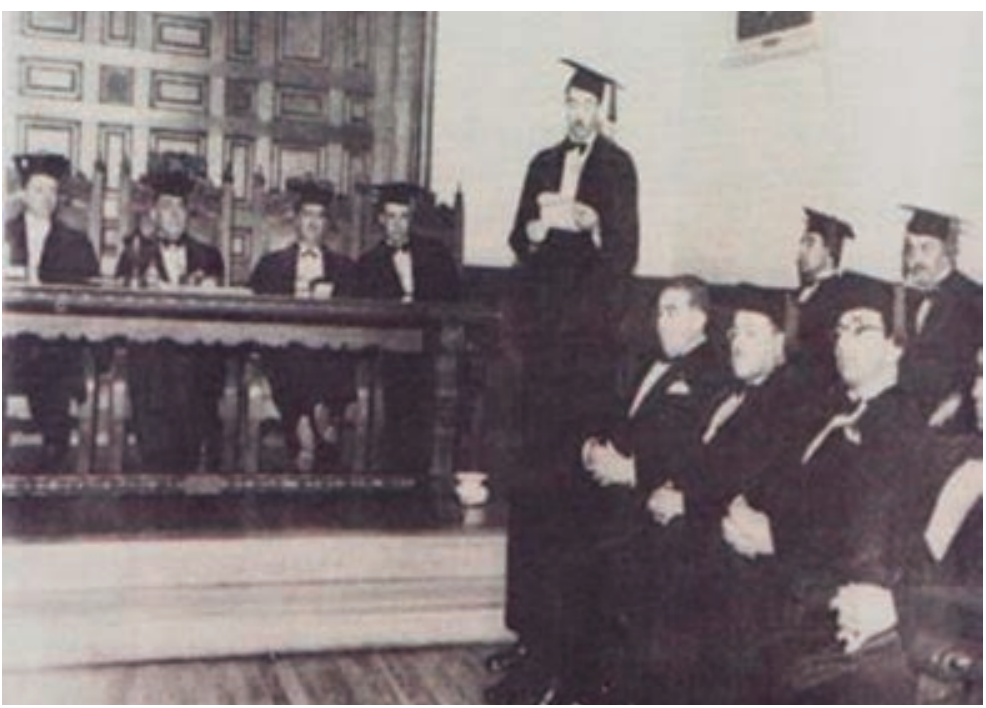

Figura 5: El Rector Gustavo Baz Prada.

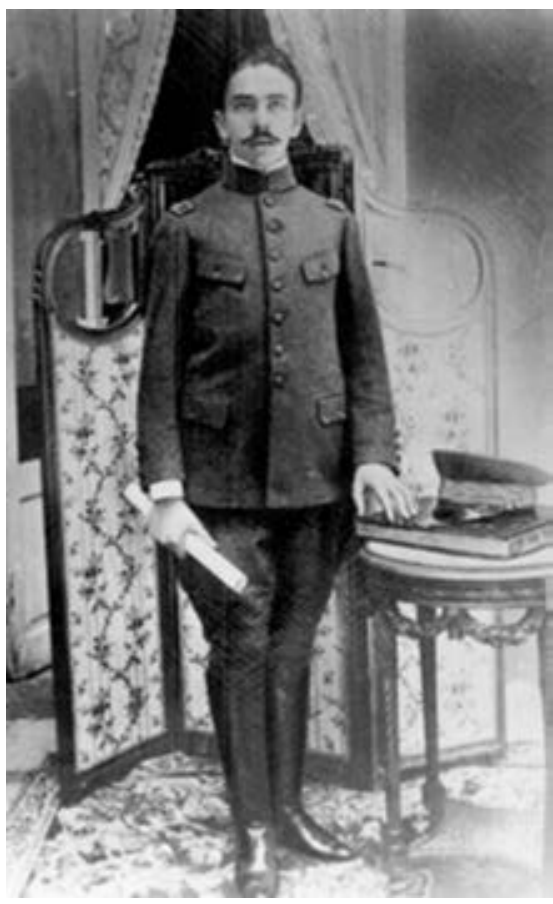

Figura 6: Gobernador del Estado de México. General Gustavo Baz Prada, 1915-1916.

82 años, se integra como senador por su estado en la LI Legislatura del Congreso de la Unión, para el periodo 1976-1982.

Premios y reconocimientos, los recibió todos. El último fue la medalla "Belisario Domínguez" que otorga el Senado de la República a mexicanos que hayan sobresalido notablemente en la defensa de las causas populares y en el servicio a la patria o a la humanidad.

Sus reglas de oro fueron:

No hablar mal de nadie

Vivir dentro de la realidad

No confundir lo supuesto con lo averiguado Ser oportuno

\section{DR. BERNARDO SEPÚLVEDA GUTIÉRREZ (1912-1985) (Figura 9)}

Lo conocí durante mi residencia y mis primeros años como cirujano del Servicio de Gastroenterología. Nunca tuve trato directo, pero siempre me llamó la atención su inteligencia, pulcritud, puntualidad, desempeño profesional y académico. Fui afortunado al conocer a 


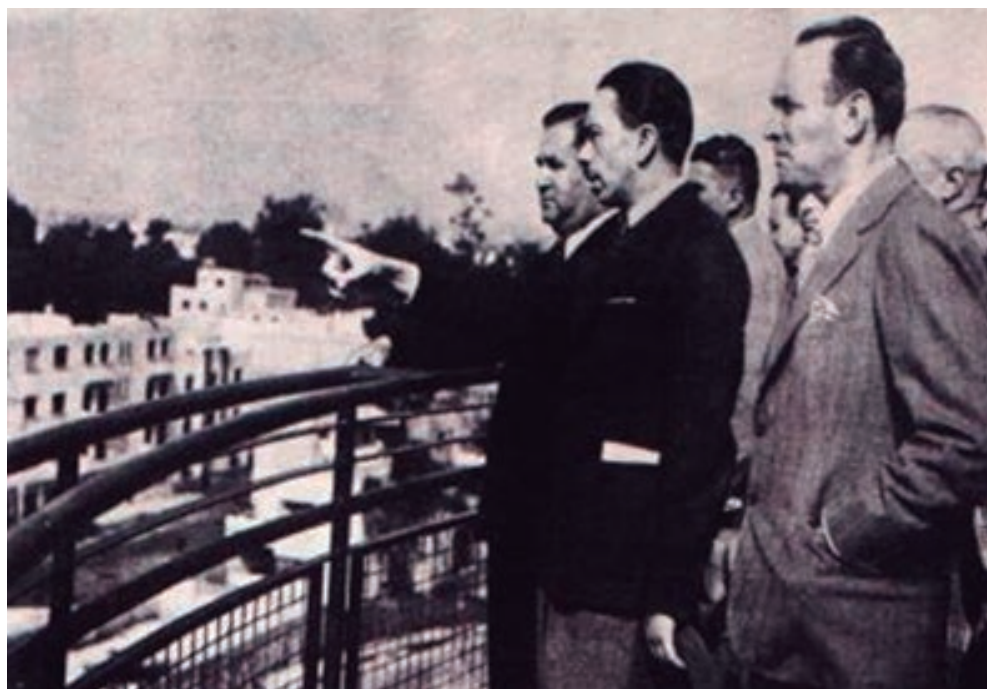

Figura 7: Supervisando los avances de Ciudad de la Salud, con el Presidente Ávila Camacho y el Dr. Salvador Zubirán.

uno de los maestros de la gastroenterología mexicana.

Originario de Monterrey, N.L., sus estudios preprofesionales los realizó en su ciudad natal, y la carrera de medicina en la Escuela de Medicina de la UNAM. En los inicios de la década de los 40 fue becado por la Mayo Foundation for Medical Research y se dedicó a las secciones de gastroenterología y medicina experimental. Se especializó en el Hospital General en donde inició su labor profesional, y de donde fue llamado a colaborar en el recién fundado Instituto Nacional de la Nutrición. Cuando fue jefe del Servicio de Gastroenterología, fue sorprendido por la invitación a colaborar en el IMSS.

En el año de 1958 se incorporó al IMSS, en donde su labor brillante, como siempre, dejó huella. Se ocupó de reorganizar y mejorar los servicios médicos, por su iniciativa se creó el Departamento de Planeación Técnica de los Servicios Médicos, implantó el primer Cuadro Básico de Medicamentos, que le dio experiencia para después presidir la Comisión Interinstitucional del Cuadro Básico de Insumos del Sector Salud, que se complementó con el Cuadro Básico de Material de Curación y Prótesis de acuerdo con el Dr. Norberto Treviño García-Manzo, último Director del HG del CMN del IMSS. Participó en la enseñanza de la Especialidad en Gastroenterología. En unión

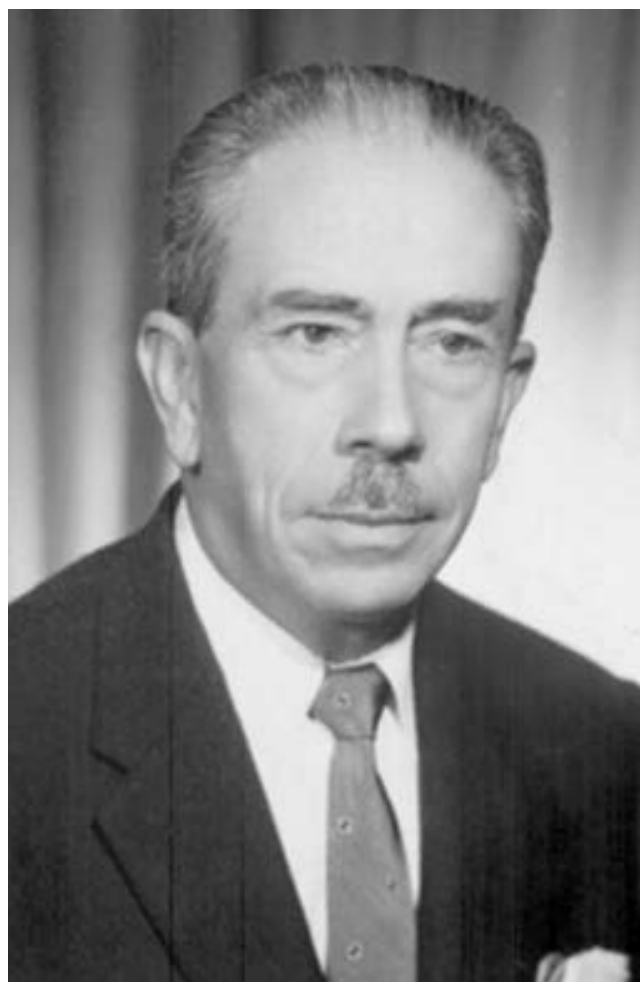

Figura 8: Dr. Gustavo Baz Prada, Gobernador del Estado de México, 1957-1963.

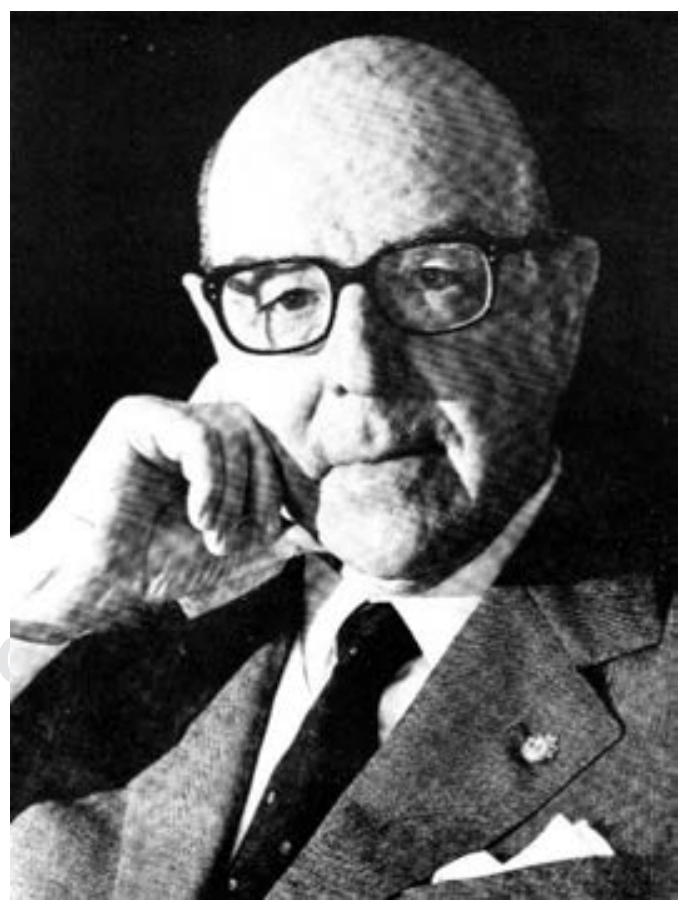

Figura 9: Dr. Bernardo Sepúlveda Gutiérrez. 
con el Dr. Luis Landa Verdugo, continuó su labor de docencia, impregnándola de sabiduría, investigación, y perfeccionando los procedimientos clínicos modernos, con metodología científica para lograr una especialidad moderna vanguardista. El Dr. Norberto Treviño, durante su función como Director, logró ponerle el nombre de Hospital General "Dr. Bernardo Sepúlveda" del CMN del IMSS.

Su participación primero en la Facultad de Medicina y posteriormente en la UNAM siempre fue notable. Inició como ayudante de la Clínica Propedéutica, y su labor fructífera como maestro a lo largo de los años lo llevó a recibir en 1979 la designación de Profesor Emérito de la Universidad Nacional Autónoma de México.

Sus méritos profesionales le permitieron ingresar al Colegio Nacional, en donde también tuvo un desempeño ejemplar. La presentación de casi doscientos trabajos científicos en reuniones nacionales y extranjeras le permitió tener una gran imagen. De todas las patologías digestivas, dos sobresalieron en su investigación, las enfermedades del hígado y la amibiasis invasora. En 1968, fundó "El Centro de Estudios sobre Amibiasis". El primer seminario fue realizado con participación de gastroenterólogos, cirujanos, patólogos y radiólogos del HG del CMN. Su éxito abrió las puertas a investigadores nacionales de otras instituciones, así como de médicos extranjeros, interesados en este tema; la enfermedad, conocida y estudiada con anterioridad por varios médicos mexicanos, tenía respuestas inconclusas y faltaba investigación, las cuales empezaron a descubrir conductas clínicas que mejoraron la evolución clínica de esta enfermedad, por otro lado, por ser enfermedad de importancia sanitaria, obligó la participación de la Secretaría de Salud y Asistencia.

En el año de 1975, con motivo del centenario del descubrimiento de la Entamoeba histolytica por Fedor Aleksandrovich Lesh en San Petersburgo, se realizó el séptimo seminario sobre amibiasis en el cual participaron expertos de USA, Canadá, Sudáfrica, India, Francia, Inglaterra, Italia, Países Bajos, Gambia, Túnez, Irak, Polonia, Suecia, Alemania, Japón, Colombia, Perú y Costa Rica.

Recuerdo una propuesta importante y trascendental del maestro Sepúlveda: dar dos comprimidos de metronidazol a todo paciente que se presentara en los servicios de urgencias de todos los hospitales. Desconozco si esta sugerencia se llevó a cabo, pero sí puedo mencionar que mis actividades en Cirugía Extramuros durante ocho años me llevaron a recorrer la mayor parte de la república y en todos y cada uno de los hospitales en donde realizamos estas actividades preguntábamos por la presencia de pacientes hospitalizados por complicaciones de la amibiasis; en todos fueron las respuestas negativas. Ante esta evidencia, considero que México dio un gran paso en salud al prácticamente erradicar esta patología.

Los doctores Hugh R Butt y Louis S Diamond, grandes investigadores de la gastroenterología confirmaron la trascendencia internacional con su participación en congresos mundiales y reuniones, particularmente sobre hepatología y amibiasis. Una comprobación más sobre su interés en la patología hepática se revela en los 56 trabajos publicados, de los cuales 45 se refieren a la glándula hepática.

Durante muchos años fue profesor en la Facultad de Medicina de la UNAM. Fue médico interno en el Hospital General (1935-1946), Jefe del Departamento de Gastroenterología del Hospital de Enfermedades de la Nutrición (1946-1962) y Jefe de la División de Estudios Superiores de la Facultad de Medicina de la UNAM (1958-1967). Fue miembro de la Junta de Gobierno de la UNAM (1964-1966), y uno de los fundadores del Instituto Nacional de la Nutrición, así como del Centro Médico Nacional del Seguro Social. Fue coordinador del Centro de Estudios sobre Amibiasis y Secretario del Consejo de Salubridad General desde 1977 hasta su muerte.

A lo largo de su vida recibió numerosos honores y reconocimientos: fue presidente de la Academia Nacional de Medicina (1957-1958), de la Asociación Médica Franco-Mexicana (1959-1961) y de la Asociación Mexicana de Gastroenterología (1960-1961). Mastership del American of Physicians (1971), profesor emérito de la Facultad de Medicina (1979), Doctor Honoris Causa por la Universidad Autónoma de Nuevo León (1982), presidente ordinario de la Organización Mundial de Gastroenterología (1982), Premio Nacional de Ciencias (1982), y vocal del Consejo Directivo del Sistema Nacional de Investigadores (1984). El Dr. Sepúlveda 
ingresó a El Colegio Nacional el 24 de octubre de 1975. Su discurso inaugural, "Conquistas y problemas de la medicina contemporánea", fue contestado por el Dr. Ignacio Chávez.

Considero que, de su brillante trayectoria académica, lo más trascendental que tiene que ver con la medicina mexicana fue su participación universitaria. El Dr. Raoul Fournier, como Director de la Escuela Nacional de Medicina de la UNAM, lo nombró Jefe del Departamento de Graduados. Esta jefatura dio origen a la actual División de Estudios de Postgrado. Después, al existir cursos de postgrado, con la aprobación del H. Consejo Universitario en el año de 1960, la Escuela Nacional de Medicina se convirtió en Facultad de Medicina. El Hospital de Especialidades del Centro Médico Siglo XXI lleva su nombre.

Los médicos que lo conocieron y colaboraron con él en los diversos campos que participó están de acuerdo en que pertenece a una generación médica que transformó la medicina mexicana.

El Dr. Bernardo Sepúlveda Gutiérrez murió el 17 de marzo de 1985 en la ciudad de México.

\section{DR. MANUEL QUIJANO NAREZO (Figura 10)}

Oriundo de San Luis Potosí, fue un hombre culto, un excelente cirujano y un gran universitario. Frecuentemente utilizaba la frase de José de Letamendi, gran médico español que decía: "el médico que siempre habla de medicina, ni medicina sabe". Junto con los profesores del curso de Cirugía General del Hospital General del CMN del IMSS, ponían mucho empeño durante la selección de los aspirantes a cirugía, investigando sus aficiones y conocimientos de cultura en general, sobre todo música y arte. Recuerdo que en un desayuno de los pocos que tuve la oportunidad de convivir personalmente con él, años después de haber dejado el IMSS, me comentó que una de sus pasiones era viajar, y que prefería tener un automóvil pasado de moda, y poder invertir ese dinero en disfrutar de paseos por el extranjero. Me dijo, con cierta tristeza, que su próximo viaje a Francia sería el último que realizaría por su edad, y por los cambios socioeconómicos que estábamos viviendo en ese tiempo.

Como cirujano notable, tiene un historial muy grande, por lo que solamente relataré lo más sobresaliente de sus actividades profesionales, sin llevar un orden cronológico de su paso por el IMSS, UNAM, SSA, organismos internacionales y como cirujano.

Durante el homenaje de cuerpo presente al Dr. Gustavo Baz Prada en el auditorio de la Facultad de Medicina de la UNAM, tuve la oportunidad de sentarme junto a mi maestro, Dr. Manuel Quijano, quien me comentó que él también había sido uno de los primeros médicos mexicanos favorecidos por el programa de becarios para el extranjero, que instituyó el Dr. Gustavo Baz Prada como Secretario de Salubridad y Asistencia en los años cuarenta. El maestro Quijano inició la residencia quirúrgica en el Hospital General de México en 1944, emigrando a los Estados Unidos de Norteamérica en el año 1945, para continuar su preparación quirúrgica en el hospital St. Lucke's, luego en la Clínica Lahey y en el Massachusetts General Hospital; perfeccionando sus conocimientos en el Hospital Saint-Louis de París. Estos viajes de preparación no fueron

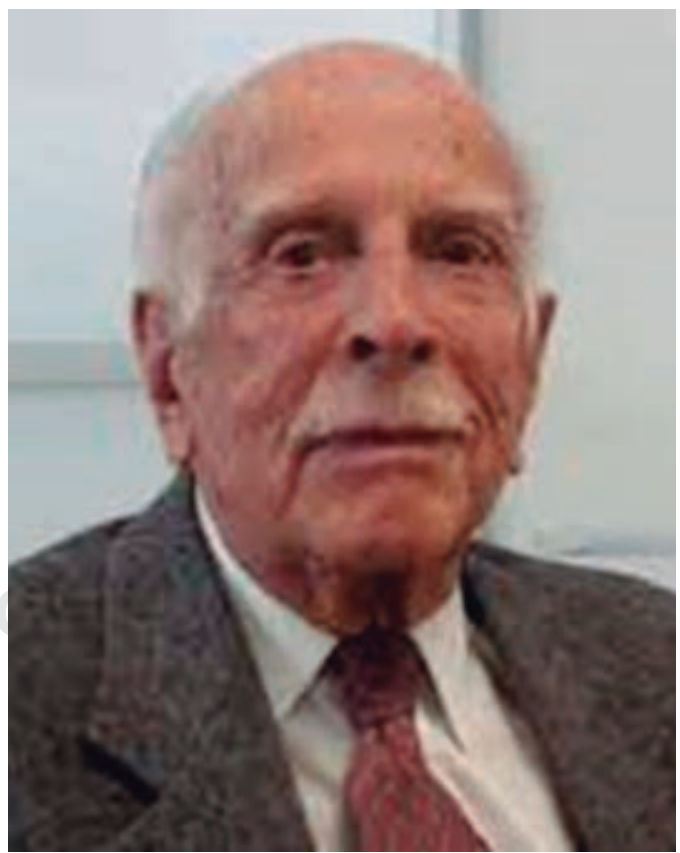

Figura 10: Dr. Manuel Quijano Narezo. 
fáciles de realizar, solamente su esfuerzo, sacrificio, tesonería, ahorro económico y deseo de triunfar le permitieron realizar ese sueño de vida. Logrando al mismo tiempo ampliar su cultura, que utilizaba con sencillez. A su regreso, sus dotes quirúrgicos le permitieron sobresalir en el Instituto Nacional de la Nutrición, lo que trascendió como el mejor cirujano del momento, por lo que el Lic. Gustavo Díaz Ordaz, Presidente electo de México, solicitó sus servicios profesionales para operar a su esposa por una litiasis vesicular.

El Dr. Ignacio Chávez, como Rector de la UNAM (1961-1966), Ilamó al Dr. Manuel Quijano Narezo para ocuparse de los Servicios Escolares, compromiso que lo obligó a dejar la cirugía y su labor en el Instituto Nacional de la Nutrición. En principio, desde este puesto logró poner orden en los trámites escolares en la Rectoría. Consolidó seis federaciones estudiantiles en una sola. Los trámites de estudios, cartas de pasantía, o fijar fecha de exámenes profesionales fueron más eficientes. Estableció oficinas satélites, descentralizando la oficina principal de servicios escolares. Diseñó una hoja para posibles trámites y operó el examen de admisión a la licenciatura, que a la fecha continúa siendo un elemento importante para la mejoría académica de la UNAM. Regresando en el tiempo, en el año de 1958, como profesor de Introducción a la Cirugía en la Escuela de Medicina de la UNAM, le permitieron realizar operaciones en perros creando el Departamento que más tarde se conoció como "Cirugía Experimental".

Luego de dos años, en 1963, renunció ante la invitación del Lic. Benito Coquet para dirigir el recién inaugurado Hospital General del Centro Médico Nacional del IMSS.

Su tránsito por nuestra máxima casa de estudios no terminó ahí. De 1968 a 1977 perteneció a la Junta de Gobierno de la UNAM, por lo que le tocó ver de cerca el movimiento estudiantil. Durante dos años (1978-1979) fue titular de la oficina de la División de Graduado de la Facultad de Medicina. En resumen, creó el examen de admisión para la licenciatura de medicina en la UNAM, fue miembro de la Junta de Gobierno y por último se entregó a la Revista de la Facultad de Medicina como su editor.
En una entrevista comentó que en esos años (década de los 60) sobresalían los trabajos de trasplantes de órganos. En México, no se había realizado ninguno y para adquirir experiencia trabajó en cadáveres y perros. Recordemos que el trasplante de riñón como tratamiento se inició en Rusia en la década de los 30, obviamente con malos resultados. El 05 de mayo del año de 1963, se reportó el primer trasplante de hígado con éxito por el Dr. Thomas Starzl. ${ }^{8}$

El 04 de diciembre de ese año en el Hospital General del CMN del IMSS se realizó el primer trasplante renal por los doctores Manuel Quijano Narezo, Federico Ortiz Quezada y Gilberto Flores Izquierdo.

En 1964, cuando fue director del Hospital General del Centro Médico del IMSS, en un acto sin duda visionario, autorizó la creación de un Servicio de Psiquiatría. Buena idea, que tuvo eco en la SSA, y que pude comprobar cuando llegué a la dirección del Hospital General de Tlalnepantla, del Estado de México, desafortunadamente tiempo después desapareció esa especialidad del organigrama de los hospitales.

El programa de reconocimiento universitario de las residencias se inició en el año de 1965 y fue nombrado titular de la residencia en Cirugía General, estableciendo un plan de rotaciones por diversas especialidades, con el objeto de capacitar al residente para operar abdomen, cuello, procedimientos de ginecología y realizar cesáreas; pasando por un servicio de ortopedia y de vascular periférico, así como de urgencias. Programa que fue aceptado e implantado en todos los cursos de Cirugía General.

Como profesor pensante y visionario, reunió a todos los profesores titulares de los servicios de cirugía general, para fundar el Consejo Mexicano de Cirugía General. El 11 de noviembre de 1978 quedó registrado ante la Secretaría de Relaciones Exteriores y la Academia Nacional de Medicina, con 1,769 cirujanos que se acogieron a un artículo transitorio. Por supuesto, el cargo de primer presidente fue su responsabilidad.

Como profesor titular de la especialidad en cirugía general por parte de la UNAM, estuvo hasta finales de 1972. El Dr. Luis Ize fue el pe- 
núltimo jefe de residentes, y por su ascenso al recién creado servicio de nutrición parenteral, dejó la jefatura vacante; la cual asumí durante los últimos cuatro meses de esa generación, por lo mismo, fui el último jefe de residentes del curso de cirugía general del Dr. Manuel Quijano Narezo.

Después de dejar la Dirección del Hospital General del CMN del IMSS, su capacidad intelectual y preparación le otorgaron un lugar para participar como Agregado Científico en la Misión de México ante la UNESCO en París, Francia (1980 a 1983). En ese tiempo, tuvo la oportunidad de convivir con el Dr. Guillermo Soberón. Cuando regresó a México, el Dr. Soberón, en ese tiempo Secretario de Salud, lo invitó a colaborar en la SSA en la Dirección General de Asuntos Internacionales (1983-1989). Fue Consejero Científico de la Organización Mundial de la Salud (1987-1989) y Presidente de ésta en el año 1989.

Fue miembro activo de Academias y Asociaciones médico-quirúrgicas, nacionales e internacionales, entre las que sobresale Miembro de la Academia de Cirugía, París. Oficial de la Ordre National du Mérite, República Francesa.

Uno de sus atributos naturales, que le permitió describir sus ideas y experiencias, fue la escritura. Realizó más de 60 artículos científicos, innumerables editoriales y dos libros: "Principios fundamentales de la cirugía". Dos tomos, 1981, obra literaria quirúrgica que fue armamento indispensable para los residentes y cirujanos de esa época, y disertaciones y repeticiones, Siglo XXI, coeditado con la UNAM. 2003. Su participación en capítulos en libros de salud y política que merecen ser señalados como "La cooperación internacional en materia de salud". La política internacional de México en el decenio de los ochenta. Fondo de Cultura Económica. 1994. "La medicina mexicana en la globalización". Un siglo de ciencias de la salud en México. Coordinado por Hugo Aréchiga y Luis Benítez Bribiesca. Fondo de Cultura Económica, Primera edición. México. 2000. Como editorialista de la revista de la Facultad de Medicina su logro más importante fue editarla para médicos generales, además de indexarla y elevar su tiraje a 20,000 ejemplares.
DR. LUIS LANDA (1926-2010) (Figura 11)

Sin duda alguna, el Dr. Luis Landa fue un Jefe de Servicio excepcional, excelente, con un carácter férreo, disciplinado y con personalidad adusta. Lo conocí durante la residencia, cuando roté por su servicio, y posteriormente fue mi jefe cuando fui seleccionado en el año de 1973 para cubrir la vacante que dejó el Dr. Gustavo Baz Díaz Lombardo.

Como todos los humanos, tenía atributos naturales y adquiridos, buenos y malos. Yo no lo debo juzgar, por lo que solamente puedo comentar lo que viví durante el tiempo que trabajé bajo sus órdenes. También líneas arriba ya fueron descritos su servicio, su distribución, las parejas de gastroenterólogos y cirujanos, las sesiones bibliográficas, radiológicas, etcétera. En todas había un compromiso de mejorar, aumentar los conocimientos y las experiencias, con la única finalidad de servir y hacer el mejor Servicio de Gastroenterología del IMSS.

Su personalidad altiva y a veces arrogante, pero principalmente de líder, quizás la comprenderemos mejor si recordamos una anécdota que contó la esposa de un cirujano que los acompañó a un congreso o reunión

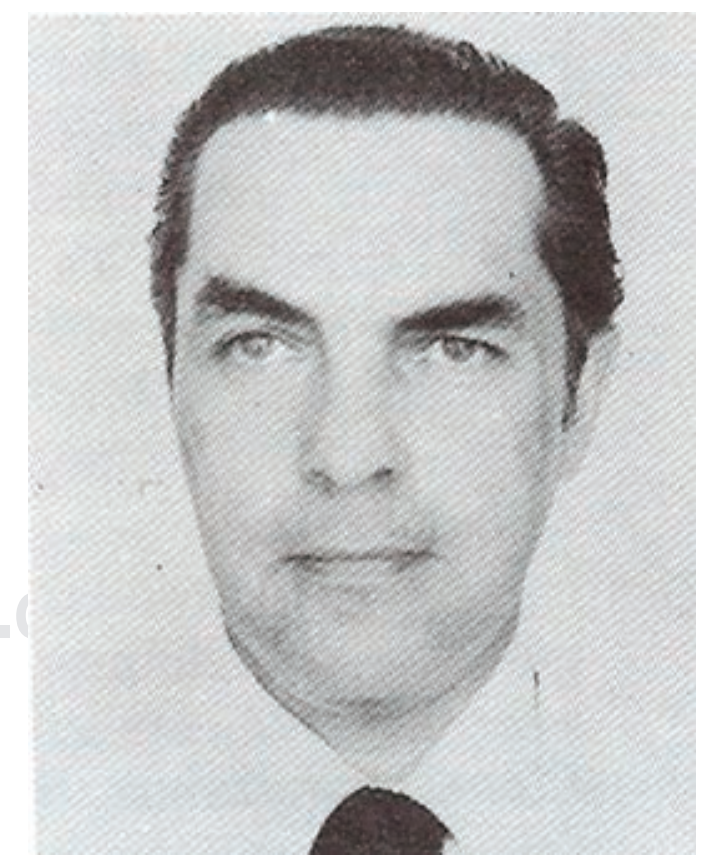

Figura 11: Dr. Luis Landa. 
médica en la provincia mexicana, trasladándose vía terrestre, con varias horas en el transporte público de ese tiempo. "Mientras que la mayoría se quejaban del calor y del polvo, en una parada obligatoria del autobús, el Dr. Landa se bajó y en los baños públicos de la terminal de camiones se lavó, rasuró, se peinó y se cambió de camisa y corbata, regresando al autobús tan fresco como si apenas estuviera iniciando el viaje, actitud que sorprendió a los viajantes".

Nunca dejaba pasar la oportunidad de participar y mejorar la imagen de su servicio. Cuando se acercaba un congreso o reunión, se suspendían las sesiones habituales, para dedicarnos a presentar nuestras ponencias y corregirlas hasta en el más mínimo detalle, oral o escrito. En el otro lado de la moneda, cuando él o alguno de sus médicos adscritos asistían a los congresos internacionales o mundiales, reproducían las novedades en las sesiones y más tarde las poníamos en práctica clínica. Todavía conservo la copia del documento de un simposio sobre páncreas realizado en el extranjero al que él asistió, y que a su regreso fue reproducido en varias sesiones, por lo que nuestro conocimiento de esta patología se actualizó inmediatamente y de manera importante. Como investigador están sus participaciones en hepatitis y en amibiasis, al lado del Maestro Sepúlveda, el protocolo para el manejo de la hipertensión portal, así como de los primeros bloqueadores $\mathrm{H} 2$, etcétera. Recuerdo la primera sesión sobre hormonas del tracto digestivo, que hoy se sigue investigando y produciendo descubrimientos importantes en la diabetes tipo 2, obesidad y otras.

Siempre estuvo abierta su puerta a la innovación, al trabajo creativo; el ejemplo está en el apoyo que le brindó al Dr. Rafael Álvarez Cordero, para crear la sala de Terapia Intensiva en el sexto piso del HG del CMN del IMSS.

En su servicio comenzó una rutina, de la cual desconozco el iniciador. En la hoja de la nota quirúrgica se realizaba un dibujo demostrativo de la cirugía efectuada, es importante mencionarlo, porque muchos residentes preferían llevar su caja de pinturas de colores, en lugar de un bisturí. Con el tiempo se hizo obligatorio, lo cual el Dr. Landa premiaba con felicitación verbal al dibujante más que al cirujano.
La imagen del Servicio de Gastroenterología, considerado como uno de los mejores, si no el mejor del país, era tomado en cuenta para que pacientes importantes de la política, de la ciencia, de las artes y de la cinematografía acudieran para recobrar su salud.

El Dr. Landa fue Director del HG del CMN por una breve temporada -cuarto director- $y$ emigró a la Subdirección Médica del ISSSTE y posteriormente a la Dirección del Hospital de Xoco del Departamento del DF. Continuó al final de su vida practicando medicina privada, hasta que sufrió con la enfermedad de Parkinson, y finalmente un sangrado del tubo digestivo complicado lo llevó a la muerte.

\section{DR. GUSTAVO BAZ DÍAZ-LOMBARDO (1933-2009) (Figura 12)}

Hijo del Dr. Gustavo Baz Prada, nació en el Distrito Federal. Fue el primer cirujano que llegó al HG del CMN del IMSS joven, con antecedentes de residencia quirúrgica en la Universidad de Minnesota (1958-1961) con el Profesor Wangesteen, y en el Instituto Nacional de la Nutrición, en donde llegó a ser jefe de residentes (1961-1963).

Como cirujano y profesor de cirugía del curso universitario, siempre tuvo excelentes relaciones con los residentes gracias a su juventud y a su carácter. Le gustaba la música, era agradable operar con él, siempre que se podía en su quirófano había sonidos agradables que aliviaban el estrés. Como amigo tuve la fortuna de conocer y de aprenderle sus gustos por los buenos aparatos de sonido y la música clásica, así como la popular. Cariñosamente le decíamos que era un cachorro de la revolución, a lo cual respondía con una sonrisa.

Los tópicos quirúrgicos en los que participó de manera sobresaliente fueron: tratamiento quirúrgico de la obesidad -cirugía no absortiva-, anastomosis de un solo plano, tratamiento de la hipertensión portal, tratamiento quirúrgico de las complicaciones de la amibiasis. En especial atención a esta patología, diseñó y mandó hacer unas agujas especiales para punción de los abscesos hepáticos amebianos, que en ese tiempo eran muy frecuentes; agujas que yo utilizo en cirugía laparoscópica cuando es necesario puncionar una vesícula aguda. En 


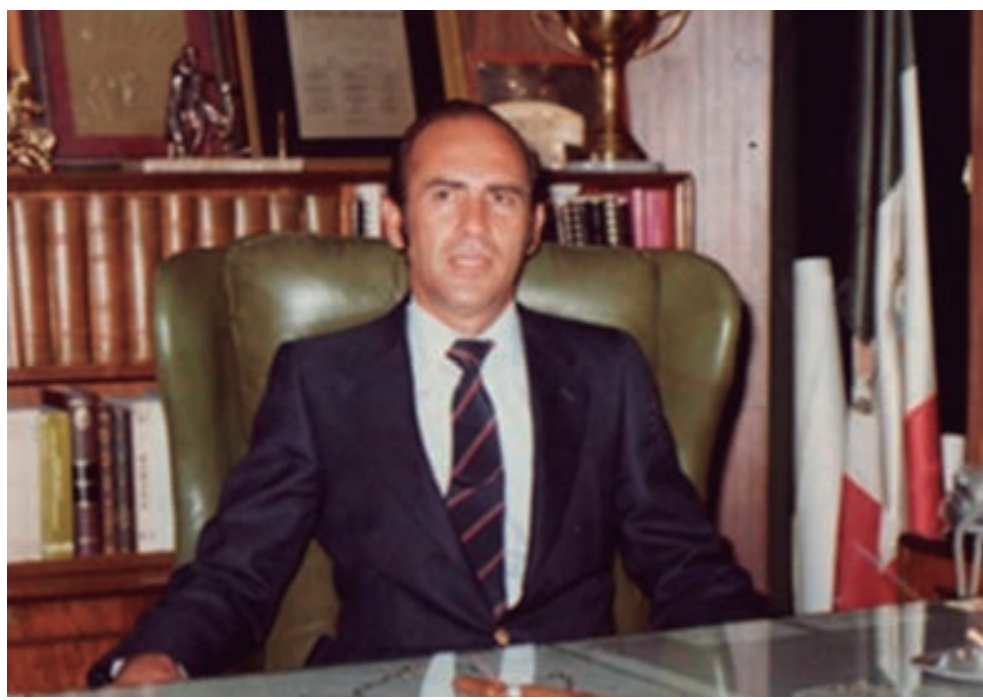

Figura 12: Dr. Gustavo Baz Díaz-Lombardo.

la cirugía de vesícula biliar y de vías biliares, se movía como pez en el agua, quién no recuerda su técnica manual sin visión para la extirpación de los piocolecistos, hidrocolecistos o de las vesículas agudas, técnica no descrita en los libros. Uno de sus mayores éxitos quirúrgicos fue la operación realizada a una paciente (MNS) durante una guardia, quien presentaba estado de choque por isquemia mesentérica aguda, que incluía yeyuno, íleon y colon derecho, fue necesario extirparle todos los segmentos intestinales mencionados, y reconstruyendo el tránsito intestinal con una anastomosis duodeno-cólica, que le permitió a la paciente sobrevivir por más de 30 años, fue un caso excepcional y único.

Otra anécdota interesante que nos permite recordar la personalidad del Dr. Baz como profesor quirúrgico la relataba con frecuencia el Dr. Antonio Escobedo, de Tampico Tamaulipas (ya fallecido), recordaba que cuando fue su residente, estando su esposa en un quirófano como paciente, el Dr. Baz le ordenó operar en el siguiente quirófano a un paciente, para que templara su coraje de cirujano, porque era necesario que tuviera esa experiencia, en razón de que el cirujano no sabe cuándo lo llamarán a operar, no importando los estados de ánimo del cirujano, y siempre debía estar dispuesto a prestar sus servicios profesionales. Cuando terminó de operar la parte importante, lo sus- tituyó y le permitió presentarse en el quirófano en donde estaban operando a su esposa.

Con su herencia genética, aunada a su inteligencia y preparación, se desarrolló en el campo quirúrgico, así como en el campo salubrista. Después de una corta vida como cirujano (10 años), decidió incursionar en el campo de la Salud Pública. Una mañana del año 1973, al terminar nuestras actividades quirúrgicas, me invitó a visitar un hospital nuevo, localizado en Ciudad Netzahualcóyotl, en el barrio de La Perla, Municipio del Estado de México, el cual formaba parte de una nueva generación de hospitales de la SSA. Después de visitarlo me hizo una pregunta, pidió mi opinión sobre la propuesta que le hizo el Dr. Jorge Jiménez Cantú, en ese entonces Secretario de Salud, lo había invitado a ser el director de ese nuevo hospital, además de desarrollar un sistema de salud regional. Mi respuesta fue inmediata. Considerando que se encontraba como cirujano en un lugar envidiable, con futuro aún más prometedor, y tomando en cuenta la distancia y el cambio radical que requería su administración, mi respuesta fue negativa. Meses después me enteré de que había solicitado permiso del CMN para iniciar sus actividades administrativas en salud, sin duda alguna, los genes políticos y salubristas habían ganado la iniciativa, por consiguiente el ganador de la plaza del Servicio de Gastrocirugía fue el que escribe, como relaté anteriormente. La cirugía de México había perdido un gran cirujano, pero había encontrado un excelente salubrista que haría muchos cambios sustanciales en la salud de primer nivel. Tiempo después me platicó que el Dr. Jorge Jiménez Cantú no aceptó su negativa, comentándole que ser pionero al instalar un sistema de salud novedoso le permitiría incrementar su imagen políticamente, abriéndole un futuro prometedor, además de llevar salud a la población más necesitada de una nueva esperanza.

Como su residente en funciones, me tocó convivir tiempos importantes en su vida profesional. Indudablemente que se desarrolló una amistad que duró hasta el último día de su vida. Primero como su residente, después como socio de consultorio y colaborador en el Estado de México, y finalmente sólo quedó la amistad que sobrevivió por casi 40 años. 
Después de la dirección del Hospital de La Perla, fue ascendido a Secretario de Salud del Estado de México, cargo que desempeñó con cuatro gobernadores, y durante los cuales creó un sistema nuevo de salud, ejemplo en la república y tomado para América Latina y África. Su liderazgo lo llevó a cambiar de nombre y función a la Secretaría de Salud del Estado de México, por el de Instituto de Salud del Estado de México. Se rodeó de médicos salubristas que él preparó en la Escuela de Salud Pública que fundó junto con la Universidad Autónoma del Estado de México, quienes lo ayudaron a resolver y a implantar los programas sanitarios que transformaron al Estado de México durante su dirección. Ahí quedaron los programas de salud mental, oftalmología y de urgencias.

El 11 de octubre de 1976 el Dr. Jorge Jiménez Cantú, Gobernador Constitucional del Estado de México, giró instrucciones al titular de los Servicios Coordinados de Salud Pública (ISEM) Dr. Gustavo Baz Díaz Lombardo para que iniciaran operaciones los Servicios de Urgencias del Estado de México (SUEM), esto a consecuencia de una inundación en Santo Domingo de Guzmán Municipio de Ixtlahuaca, ya que en ese tiempo no se contaba con cuerpos de emergencia especializados en el estado. Si no fue el primer Servicio de Urgencias a nivel estatal, sí fue uno de los primeros en donde se prepararon jóvenes físicamente, con técnicas actualizadas y humanizadas, enfocadas a la atención prehospitalaria y de rescate de víctimas.

Fundó la Escuela de Salud Pública del Estado de México para capacitar médicos sanitaristas que eran indispensables para la demanda inesperada por los programas implantados de los Servicios Estatales de Salud. Por supuesto que produjo rechazo, comentarios adversos, sobre todo de los salubristas tradicionales de México, porque quitó la hegemonía de la Escuela de Salud Pública, dependiente de la SSA, la única que producía ese tipo de especialistas. Hasta el año 1991, 630 profesionales habían terminado el curso y 134 estaban en proceso.

La esencia operativa de la regionalización de los servicios de salud fue el tramo de control denominado Unidad de Atención Primaria a la Salud (UAPS). Cada coordinación municipal se dividió en microrregiones en donde se ubicaban de 2,500 a 3,000 habitantes (de 450 a 500 familias en promedio). De tal forma, cada coordinación municipal controlaba 10 microrregiones, con un promedio de 30 a 60 mil habitantes.

Considero que su mayor logro en su desempeño como médico salubrista fue el haber ideado, creado y puesto en marcha el programa PRODIAPS, se implantó en 2,350 microrregiones del Estado de México, y se tenía contratado un recurso humano denominado operador de programa de atención primaria (PRODIAPS), que eran oriundos de la comunidad en la que trabajan y con un nivel de educación primaria en las aéreas urbanas; en todos los casos participaban y aprobaban obligatoriamente el curso específico. Estos trabajadores estaban en permanente proceso de capacitación, y la experiencia que desarrollaban les permitió constituirse como verdaderos técnicos en salud. Su trabajo se mejoró al dotarlas de instrumentos digitales, para la recopilación de datos censales de las microrregiones a su cargo. Con esta información, el diagnóstico de salud familiar fue desarrollado en el Estado de México como un avance e innovación con esta técnica y su propósito fundamental fue cubrir los objetivos del diagnóstico de salud, pero iniciando su acopio de datos desde el núcleo familiar, que se consideraba para estos propósitos como una unidad epidemiológica social, sujeto de estudio descriptivo y analítico. Este programa tuvo difusión y aceptación mundial. Sus programas de salud dental (sal yodatada y fluorada) y de oftalmología fueron copiados y adoptados en países europeos, africanos y en América latina. En el programa oftalmológico, demostró que la niñez mexiquense tenía problema visual en el $35 \%$ de los casos y no del $10 \%$ como se mencionaba en la literatura.

Después del macrosismo del año 1985, se reestructuraron los Servicios de Salud del Distrito Federal y de los municipios conurbados del Estado de México. De los hospitales programados por el Gobierno Federal, por medio de la Secretaría de Salud logró que se construyeran en los municipios de Naucalpan, Atizapán, Cuautitlán, y Nezahualcóyotl, con el fin de detener la afluencia de pacientes de esos municipios a los hospitales del D.F. Además de los hospitales mencionados, se deben agregar 
la construcción de 70 hospitales municipales y 200 clínicas o consultorios en ese periodo. Recibió a los servicios de salud del Estado de México con 750 trabajadores y lo entregó 20 años después con más de 20,000 y un historial importante.

Su labor en la SSA continuó al dejar el ISEM (Instituto de Salud del Estado de México), fue Director de Asuntos Sectoriales e Internacionales de la SSA, y posteriormente participó en los programas de atención a la salud a población abierta. También formó parte de la Dirección de programas y desarrollo de los Servicios de Salud Pública en el DF, y en la Subsecretaría de Salud del gobierno del Distrito Federal. Regresó tiempo después a la SSA en donde se desempeñaba como asesor de la Subsecretaría de innovación y calidad, cuando lo sorprendió la enfermedad que lo llevó a la muerte.

Fue fundador de la Asociación Mexicana de Cirugía General, miembro de la Asociación Mexicana de Gastroenterología, y del Colegio Americano de Cirujanos. Su preparación académica de postgrado la continuó con diplomados gerenciales dedicados a la superación personal y a la mejor aplicación a la salud regional y municipal.

Sus actividades docentes fueron: profesor en las especialidades de cirugía general y gastroenterología quirúrgica de la Facultad de Medicina, Maestro en Salud Pública en las facultades de medicina de la Universidad Autónoma del Estado de México y en la UNAM, profesor en la maestría en Administración de hospitales en la facultad de contaduría y administración de la UNAM y profesor invitado en diversas facultades de medicina de la república, así como en academias y asociaciones médicas.

Su participación en academias, sociedades y asociaciones profesionales fueron múltiples y muy variadas, por señalar algunas. Chairman mundial en el 23 Congreso Mundial de Informática Médica en Suiza. Vicepresidente de la Asociación Mexicana de Escuelas de Salud Pública en América Latina y posteriormente
Presidente. Vocal de la Asociación Mexicana de Salud Pública. Fundador y presidente de la Sociedad de Salud Pública del Distrito Federal.

Su presencia a nivel internacional revela que participó en conferencias y en la implantación de diversos programas de salud en los siguientes países: Cuba, Venezuela, Perú, Costa Rica, Holanda, Suiza, Egipto, Canadá, Francia.

Siempre fue un amante de los deportes, practicaba ejercicios físicos, nadaba, esquiaba, tiraba con arco y rifle olímpico. Su pasión fueron los veleros, por lo que año con año se desplazaba a la ciudad de Miami Florida, EUA, para asistir a la Expo boat. Su carácter juvenil y su sencillez le permitieron ser un hombre carismático que siempre tuvo amigos, en los hospitales y en el inmenso campo de la salud pública, nunca lo vimos contrariado o enojado, por lo que se considera que fue un hombre amable. El 22 de abril del año 2009 los periódicos de la ciudad de Toluca comunicaron su deceso, al no resistir una cirugía de corazón.

\section{REFERENCIAS}

1. Gándara SL. Gustavo Baz. El médico. Editorial Libros de México, S.A. Edición patrocinada por el Lic. Juan Highland Gómez. 1981.

2. Landa NA, Hernández EA. Germinal: vida de un pueblo y un hombre. Edición particular. p. 175.

3. Anzaldo RV. Emérita Nuño Amezcua. Gustavo Baz. El Hombre. Editor Víctor Anzaldo y Regalado. p. 274.

4. Medina NH. Gustavo Baz, Guerrillero de Emiliano Zapata. 3a ed. Homenaje a los 92 años de una vida fecunda. pp. 91-100.

5. Landa NA, Hernández EA. Germinal: vida de un pueblo y un hombre. Edición particular. p. 62.

6. Gándara SL. Gustavo Baz. El médico. Editorial Libros de México, S. A. Edición patrocinada por el Lic. Juan Highland Gómez. 1981. p. 3.

7. Landa NA, Hernández EA. Germinal: vida de un pueblo y un hombre. Edición particular. p. 172.

8. Orozco-Zepeda H. Un poco de historia sobre el trasplante hepático. Rev Invest Clin. 2005; 57: 124-128.

Correspondencia:

Dr. David Olvera Pérez

E-mail: docolvera2@gmail.com 